\title{
A NOVA CONFIGURAÇÃO DO PARADIGMA COGNITIVO NA CIÊNCIA DA INFORMAÇÃO: CONTRIBUIÇÕES AO PROCESSO DE CONHECER DO PROFISSIONAL DA INFORMAÇÃO
}

\author{
LA NUEVA CONFIGURACIÓN DEL PARADIGMA \\ COGNITIVO EN LA CIENCIA DE LA INFORMACIÓN: \\ CONTRIBUCIONES AL PROCESO DE CONOCER DEL \\ PROFESIONAL DE LA INFORMACIÓN
}

\begin{abstract}
Paula Regina Dal' Evedove - p.dallevedove@gmail.com Doutoranda em Ciência da Informação pela Universidade Estadual Paulista (UNESP/Marília).
\end{abstract}

Mariângela Spotti Lopes Fujita - fujita@marilia.unesp.br Doutora em Ciências da Comunicação pela Universidade de São Paulo (USP). Docente do Departamento de Ciência da Informação da Universidade Estadual Paulista (UNESP/Marília).

\section{RESUMO}

Introdução: Os estudos em torno da cognição humana representam uma perspectiva relevante em Ciência da Informação, considerando-se as ações subjetivas dos profissionais da informação e o processo dialógico que deve permear a atuação dos sujeitos que lidam com a organização e representação da informação.

Objetivo: Explora a abordagem do ponto de vista cognitivo na Ciência da Informação e suas novas configurações mediante as necessidades contemporâneas de informação para refletir sobre o processo de conhecer do profissional da informação mediante a realidade social que permeia os contextos de informação. 
Metodologia: Reflexão sobre aspectos teóricos que tratam do desenvolvimento cognitivo para discutir as implicações da abordagem cognitiva em Ciência da Informação e sua evolução no escopo do processamento e representação da informação.

Resultados: As pesquisas em Ciência da Informação devem considerar questões de ordem cognitiva e social que permeiam o processamento da informação e o processo de conhecer do profissional da informação, pois as estruturas de conhecimento devem ser explicadas a partir do contexto social dos sujeitos cognoscentes.

Conclusões: Tem-se a necessidade de investigar o processo de conhecer do profissional da informação sob o viés da abordagem sociocognitiva, objetivando novos subsídios para a compreensão da relação informação (manifestações cognitivas) e suas implicações na dimensão social.

Palavras-chave: Ciência da Informação. Ciências Cognitivas. Paradigma cognitivo. Processo de conhecer. Profissional da Informação.

\section{INTRODUÇÃO}

As teorias cognitivas contribuem para o fortalecimento e amadurecimento epistemológico da Ciência da Informação, pois os modos de pensar, manipular informações e apropriar-se do conhecimento são fenômenos de cunho cognitivo que cercam muitas das atividades e problemas investigados pela área (INGWERSEN, 1996).

As discussões relativas à mente humana fazem parte das abordagens das Ciências Cognitivas e, portanto, não cabe aos cientistas da informação trabalhar com esta essência fenomenológica. Todavia, os estudos em torno da cognição humana representam uma perspectiva relevante em Ciência da Informação, considerando-se as ações subjetivas dos profissionais da informação e o processo dialógico que deve permear a atuação dos sujeitos que lidam com a organização e representação da informação.

Em razão da diversidade de aspectos de natureza comum entre a Ciência da Informação e as Ciências Cognitivas, muitos dos quais pouco aprofundados ou mesmo inexplorados, torna-se relevante que a área avance no estabelecimento de estudos que cerquem questões que envolvam a ação humana, a partir da realidade social objetiva. Este entendimento versa pela interdisciplinaridade entre a Ciência da Informação e as Ciências Cognitivas assentar-se no fato das teorias cognitivas conceberem os meios necessários de se compreender, refletir e pensar o conhecimento humano que, em Ciência da Informação, abre as portas para a 
observância do processo de conhecer do profissional da informação enquanto sujeito cognoscente.

Neste sentido, toma-se como pano de fundo teórico a abordagem do ponto de vista cognitivo na Ciência da Informação e suas novas configurações mediante as necessidades contemporâneas de informação para refletir sobre o processo de conhecer do profissional da informação mediante a realidade social que permeia os contextos de informação. Para tanto, busca-se amparo nas teorias que tratam do desenvolvimento cognitivo nas Ciências Cognitivas a fim de refletir sobre o desenvolvimento da abordagem cognitiva nos traços científicos da Ciência da Informação e sua evolução frente as críticas a ela tecidas, ensejadas, sobretudo, no escopo do processamento e representação da informação.

É oportuno salientar que não se busca neste estudo adentrar nas densas explicações cognitivas de caráter científico enquanto um dos fenômenos mais intrigantes do ser humano. O intento, aqui, é que tal discussão propicie novas reflexões a respeito das características e variáveis que permeiam as bases conceituais da Ciência da Informação e regem o seu percurso interdisciplinar com as Ciências Cognitivas visando o aprofundamento do arcabouço teórico e metodológico das atividades destinadas ao processamento e representação da informação em contextos informacionais e, também, para 0 avanço de investigações sobre 0 processo de conhecer do profissional da informação enquanto sujeito cognoscente.

\section{CIÊNCIA DA INFORMAÇÃO E CIÊNCIAS COGNITIVAS: ALGUMAS CONSIDERAÇÕES}

Em meio as várias concepções presentes na literatura especializada (BORKO, 1968; MIKHAILOV; CHERNYI; GILYAREVSKYI, 1980; SARACEVIC, 1999; Le COADIC, 1996), dentre outros, adota-se neste estudo o entendimento de que a Ciência da Informação constitui-se como um campo sustentado por problemas informacionais, uma vez que se preocupa com a transmissão de conhecimento para aqueles que dele necessitam. Portanto, seu cenário está vinculado à responsabilidade social, sendo também considerada uma ciência social, visto que se preocupa com o esclarecimento de um problema social concreto - o problema da informação (WERSIG; NEVELLING, 1975). 
Reconhecidamente, a Ciência da informação, mais que um infuso teórico, é um campo científico que funda-se sobre um esquema de trabalho que compreende o entrelaçamento de conceitos científicos gerais, modelos e conceitos ordinários, sob os aspectos de seu desenvolvimento e de sua possível combinação do ponto de vista da resolução de problemas do conhecimento (CAMPOS; VENÂNCIO, 2007, p. 116). Assim, relaciona-se com a transferência da informação almejada entre o gerador e o ser social e, portanto, volta-se para o estudo da informação e das inúmeras situações e processos decorrentes desse fenômeno (BELKIN; ROBERTSON, 1976).

De modo geral, a proposta básica desta concepção é abordar cientificamente os fenômenos que envolvem a informação enquanto componente propulsor do conhecimento humano. Esta característica vai ao encontro com o interesse de muitos outros campos científicos que trabalham com a informação em suas mais variadas especialidades, cujo objetivo comum é compreendê-la e comunicá-la. Voltam-se, sobretudo, para o entendimento do comportamento humano diante da informação e sua utilização.

Nas Ciências Cognitivas o ato de conhecer é produzir e reproduzir, ou seja, o espírito deste campo científico assenta-se na concepção de que "conhecer é simular" determinados modelos do fenômeno e efetuar sobre eles manipulações ordenadas, pautando-se na representação - aspecto que caracteriza o modo racional de conhecimento (DUPUY, 1996). De modo geral, o cerne das contribuições das Ciências Cognitivas é propiciar subsídios que ajudem os diferentes campos científicos a compreenderem o significado da informação (o modo de percebê-la, tratá-la e comunicá-la), do conhecimento e do saber humano.

$\mathrm{Na}$ Ciência da Informação o processo de conhecer dos sujeitos é investigado na medida em que a informação, enquanto fator que propicia o conhecimento, necessita ser observada sob a ótica do comportamento humano. Tal entendimento centra-se no fato de que a "[...] geração de conhecimento é uma reconstrução das estruturas cognitivas, ou seja, uma modificação em seu estoque mental de saber acumulado, resultante de uma interação com uma informação percebida e aceita" (BARRETO, 2003, p. 58). Nessa visão, a produção de um novo conhecimento ocorre no momento em que uma dada informação, desconhecida até o momento, é 
incorporada e modifica os estados cognitivos do sujeito, resultando no novo conhecimento.

Nesse contexto, o fundamento sobre 0 qual se desenvolve a interdisciplinaridades entre a Ciência da Informação e as Ciências Cognitivas, tão necessária na atual conjuntura dos saberes, assenta-se no fato das Ciências Cognitivas conceberem os meios necessários de se compreender, refletir e pensar o conhecimento humano. Isso porque os principais enfoques nas Ciências Cognitivas são dados aos processos cognitivos formados pela memória, raciocínio, atenção, percepção, compreensão, pensamento, conceitualização, capacidade de solucionar problemas e a função da linguagem no contexto da representação informacional a partir do estudo da estrutura do conhecimento humano (De MEY, 1982).

Por sua vez, a vinculação destas operações mentais na Ciência da Informação contribui diretamente para a compreensão de questões relativas ao processamento e representação da informação, considerando-se o necessário desenvolvimento de propostas investigativas voltadas aos fluxos de informação e conhecimento multidirecionados, isto é, "[...] que pensem a organização e recuperação da informação desde o momento da gênese informacional." (GALVÃO, 2008, p. 209). Desse modo, a preocupação fim de ambos os campos científicos é o humano, na medida em que os aspectos informacionais tangenciam com os processos cognitivos, com vistas a '[...] desvendar os 'mecanismos' da mente humana sob o ponto de vista social ao qual se apresentam" (MAIMONE; SILVEIRA, 2007, p. 56).

Em linhas gerais, o percurso de relações interdisciplinares com as Ciências Cognitivas a partir do final da década de 1970 tem sido marcado por diversas publicações, estudos e práticas que discutem o enfoque cognitivo na Ciência da Informação (BELKIN, 1990; BORGES, 2003; BROOKES, 1980; INGWERSEN, 1996; LIMA, 2003; LINARES, 2004; ROZADOS, 2003) dentre outros. As principais influências dessa interface que contribui para a compreensão dos processos cognitivos envolvidos na produção, comportamento e utilização de produtos e serviços informacionais centram-se nos estudos de usuário; nos estudos de categorização e recuperação da informação; nos estudos em torno do ambiente organizacional; bem como nos estudos de tratamento da informação em que são consideradas as faculdades mentais dos sujeitos. Neste último, os principais elos 
dessa relação é o processamento e a representação da informação, num contínuo de tratamento e representação simbólica da informação por meio dos processos cognitivos. Tal entendimento advém do próprio ato de representar, o qual significa elucidar materialmente um determinado elemento, de modo que as características do representado sejam expressas e tornadas compreensíveis num todo coerente e distinto. Sobre isto, Job (2008, p. 376) salienta que a finalidade dessa representação é viabilizar "[...] a comunicação e o relacionamento social: o relacionamento entre as pessoas, o meio e os objetos representados."

Ademais, Saracevic (1996, p. 47) que a principal razão que sustenta essa interface decorre do núcleo da Ciência da Informação ser constituído pela recuperação da informação e, consequentemente, relacionar-se com os processos cognitivos da comunicação humana de caráter científico e prática profissional, ambos "[...] voltadas para os problemas de efetiva comunicação do conhecimento e de seus registros entre os seres humanos [...]". Assim, ao lidar com o processamento técnico da informação com vistas a sua recuperação em sistemas de informação, a Ciência da Informação apresenta-se como uma ciência de cunho cognitivo e, por isso, "[...] as eternas e intransponíveis dúvidas metafísicas, relativas à estruturação, à essência e à efemeridade do conhecimento humano interferem no processo de organização do conhecimento [...]" (ALVARENGA, 2003, p. 38-39).

Uma vez apresentada a interdisciplinaridade entre a Ciência da Informação e as Ciências Cognitivas no âmbito do processo de conhecer dos sujeitos cognoscentes inseridos nas atividades de processamento e representação da informação, parte-se para uma breve exposição das principais teorias sobre o desenvolvimento cognitivo nas Ciências Cognitivas direcionadas a compreensão do comportamento humano.

\subsection{Aspectos Teóricos em Torno do Desenvolvimento Cognitivo}

Assim como a Ciência da Informação, as Ciências Cognitivas é um campo ainda pouco consolidado e em pleno processo de construção em um terreno difícil que envolve 0 trabalho da mente se auto-investigando com pretensões à cientificidade. Na visão de Gardner (1996), este campo científico representa um esforço contemporâneo com fundamentação empírica em torno dos 
questionamentos epistemológicos relativos à natureza do conhecimento - seus componentes, suas origens, seu desenvolvimento e seu emprego. Para o referido autor, as características ou aspetos associados com os esforços cognitivo-científicos de maior importância nas Ciências Cognitivas são constituídos por cinco aspectos fundamentais, sendo que os dois primeiros incorporam os pressupostos centrais e os últimos três representam aspectos metodológicos ou estratégicos do campo em questão (GARDNER, 1996).

De modo geral, o primeiro aspecto aponta que as atividades cognitivas devem respaldar-se apenas nas representações mentais, em um nível separado do biológico/neurológico e do sociólogo/cultural; o segundo defende a crença de que o computador é essencial para a compreensão da mente humana - o modelo mais viável de como a mente humana funciona; o terceiro aspecto refere-se à decisão de não enfatizar alguns fatores que são importantes para o funcionamento cognitivo, porém intrincam o empreendimento cognitivo-científico, tais como fatores afetivos ou emocionais, o contexto que cerca qualquer ação ou pensamento, ou à análise histórica ou cultural; o quarto refere-se à esperança interdisciplinar entre os campos na busca por uma Ciência Cognitiva unificada e; por fim, o quinto aspecto abriga o anseio epistemológico em torno das questões e preocupações substanciais do campo visando sua autonomia nas ciências (GARDNER, 1996).

Sob essa perspectiva, as Ciências Cognitivas ocupam-se em "[...] esclarecer os processos realizados pelos humanos para codificar, armazenar e utilizar a informação científica", em função dos tipos de conhecimento; nível de experiência; passos epistemológicos; estratégia do pensamento; e o fator emotivo-afetivo existente no processo de pensamento (BERNARD, 1995, p. 59). Na visão de Linares (2004, p. 34), este campo científico representa "[...] a troca do dirigismo dominante para a defesa dos aspectos subjetivos e significativos da experiência psicológica, e trata de explicar e de tratar o que passa no mundo interior."

O objeto de estudo das Ciências Cognitivas é a mente a partir do desenvolvimento de teorias gerais que explicam a capacidade cognitiva dos seres humanos que, por sua vez, pauta-se no princípio de resolução de problemas. Basicamente, as Ciências Cognitivas pautam-se pelos seguintes princípios: a) não existe dualismo entre a mente e o cérebro: um problema em nível físico vai se repetir em nível mental; b) o homem pode simular artificialmente os processos cognitivos 
mentais e; c) o conhecimento é uma representação simbólica do real (ROZADOS, 2003, p. 86).

Nas Ciências Cognitivas, o sistema cognitivo (processamento de informação) compreende representações na forma de estrutura de dados e processos de operação dessas representações, em que a mente seria a faculdade de modelizar. Portanto, a essência dessas ideias é a percepção, a cognição e os processos cognitivos pautados no paradigma cognitivo representacionista e computacionista. A partir do século $X X$ os estudos sobre a cognição humana receberam um enfoque diferenciado, o que resultou num avanço considerável em torno das investigações nas Ciências Cognitivas. Por sua vez, as correntes dominantes neste campo científico estão baseadas no objetivismo ao estabelecerem a separação do sujeito (mundo da mente) e do objeto (mundo das coisas).

Ao longo da história, verifica-se que as tentativas de desvendar a complexidade, riqueza e sutileza do funcionamento da mente humana requerem o suporte de diversos paradigmas que conduzem a relevância de certos atributos e ao descarte de outros. Isto porque nas Ciências Cognitivas tem-se o entendimento de que caracterizar a cognição por meio de uma única conceituação respalda numa perspectiva de improvável êxito, sendo a realidade demasiada complexa para se aceitar que uma única abordagem revele todas as nuances da cognição enquanto elemento complexo e multidimensional (De MEY, 1982).

Portanto, a tentativa de compreender a mente humana nas Ciências Cognitivas assenta-se na exposição de um corpo de paradigmas que investigam as diversas vertentes e inerências dessa especificidade, sobretudo, no que tange ao comportamento humano, a saber: a abordagem behaviorista; o paradigma piagetiano; a perspectiva neopiagetiana; a abordagem do processamento informacional; e o paradigma contextual. Ademais, outras duas abordagens começam a ser referenciadas: a biológico-maturacional e a abordagem do conhecimento baseado em teorias. Juntos, esses paradigmas formam o corpo de conhecimentos que se complementam e integram os vários olhares sobre a mente.

A primeira perspectiva, abordagem behaviorista, defende que a cognição modifica o comportamento humano. Em outras palavras, a aquisição de novas informações dá-se mediante um novo comportamento cognitivo, ou mesmo pela 
observação dos atos de outros sujeitos. Este último denominado de processo de aprendizagem social.

Por sua vez, no paradigma piagetiano evoca-se o funcionamento cognitivo e seu papel fundamental enquanto propulsor do desenvolvimento a partir de uma perspectiva evolutiva - o desenvolvimento cognitivo está relacionado com as estruturas cognitivas que se organizam de acordo com o nível de inteligência. Sobre isto, Piaget (1971) esclarece que a estrutura cognitiva é construída em etapas ou conjunto de etapas, em que a construção do conhecimento ocorre pela ação recíproca e interativa do sujeito e o seu meio. Neste, parte-se do pressuposto de que o conhecimento deve viabilizar ao sujeito uma adaptação ao ambiente a partir de três mecanismos - assimilação, acomodação e equilibração (MUSSEN et al., 1988).

$\mathrm{Na}$ teoria defendida pelos neopiagetianos, as habilidades cognitivas possibilitam ao sujeito a diferenciação de informações com intuito de determinar subobjetos para atingir uma meta, cujo foco é "[...] a especificidade do domínio das habilidades cognitivas e dos aumentos evolutivos da capacidade mental" (FLAVELL; MILLER; MILLER, 1999, p. 24). Esta perspectiva resgata como paradigma básico à concepção estruturalista piagetiana, estabelecendo uma recorrência a outros paradigmas, a fim de preencher as lacunas evidenciadas na teoria anterior. Em linhas gerais, as incompletudes são expressas por meio da variabilidade do comportamento em função do contexto social, providas pelo processamento da informação.

Por conseguinte, a abordagem do processamento da informação propiciou uma análise minuciosa e detalhada do desenvolvimento cognitivo ao conceber a mente como um sistema complexo de caráter lógico e não físico, buscando legitimarse por meio de uma analogia estabelecida entre a mente humana e o computador. Nesta perspectiva, a mudança cognitiva seria impulsionada pela automatização dos processos mentais, com vistas a uma reorganização do conhecimento e mudança comportamental. Contudo, dentre as vastas limitações desta abordagem, talvez a mais significativa seja o regresso de trazer a mente de volta às Ciências Humanas devido à ênfase acentuada nos processos de informação, negligenciando-se a descoberta e descrição formal dos processos de produção de significados que emergem da interação entre os seres humanos e o mundo (BRUNER, 1997). Assim, a grande lacuna que se estabelece respalda-se no fato da mente humana, 
primordialmente, ter a capacidade de vivenciar a consciência de seus processos, uma vez que a consciência constitui um princípio fundamental.

Paralelamente, o paradigma contextual ou vygotskyana valoriza a questão da construção de significados e da consciência, por entender que as interações no ambiente social são propulsoras do desenvolvimento cognitivo atual e futuro. As concepções anteriores advogam uma constituição intrinsecamente individual e interna do desenvolvimento cognitivo, em que o contexto social atua enquanto facilitador ou dificultador do desenvolvimento. Contrariamente, o posicionamento desta abordagem baseia-se no fato de que o desenvolvimento humano é constituído a partir do coletivo - perspectiva sócio-interacionista, cuja gênese da consciência é atribuída a internalização dos processos interativos estabelecidos no contexto social, "[...] vinculados por meio de uma relação indissociável de construção e reconstrução dinâmica ao longo de todo o processo de desenvolvimento." (SANTANA; DIAS; ROAZZI, 2006, p. 75). Assim, o conhecimento é construído no decorrer de interações do sujeito com a sociedade, promovendo o aprendizado e o desenvolvimento de processos mentais superiores.

A abordagem biológico-maturacional, sustentada pela neurociência cognitiva, enfatiza que o processo de mudança cognitiva ocorre pela dotação genética e à maturação cerebral. Nesta, a concepção da mente refere-se a um processo que abrange operações conscientes e inconscientes, ou seja, o processo de conhecer e o processo da vida. Aqui, meio e sujeito estão imbricados, cuja "[...] história de vida de todo organismo é uma história de mudanças estruturais coerente com a história de mudanças estruturais do meio em que ele existe, realizada através da contínua e mútua seleção das respectivas mudanças estruturais." (MATURANA, 1997, p. 62). A principal contribuição desta abordagem tem sido no sentido de revelar a existência de uma relação entre alguns aspectos da consciência e as operações e sistemas cerebrais específicos. Contudo, esta abordagem abandona o paradigma de representação, tão necessário para a produção e organização da informação e do conhecimento.

Por fim, tem-se a abordagem do arcabouço teórico conceitual difundido como Cognição Situada. Nesta, a dicotomia sujeito-objeto deixa de ser enfatizada, na medida em que "[...] a realidade é vista como algo que depende do seu observador. É o próprio ser humano que constrói o seu mundo, na dinâmica do viver, incessante 
e interativo" (VENÂNCIO; BORGES, 2006, p. 31). Assim, a cognição situada aponta que $o$ ato cognitivo é experimental e situado - interação congruente entre o sujeito em seu meio.

Mediante a exposição das diferentes teorias que cercam a mente humana nas Ciências Cognitivas, evidencia-se a necessidade de se analisar o sujeito enquanto ser pensante dentro do meio que o cerca para que o processo de conhecer ocorra de maneira mais proveitosa e satisfatória, independente dos objetivos subjacentes envolvidos no desenvolvimento cognitivo. No que tange a Ciência da Informação, mais precisamente as atividades realizadas nos contextos de informação, acreditase que tal prerrogativa deva ser considerada e incorporada nas pesquisas destinadas ao processamento e representação da informação, pois o processo de conhecer, seja para gerar coletivamente novos conhecimentos (profissional) ou para adquirí-los (usuário) exige condições e ambiências favoráveis.

\section{O PARADIGMA COGNITIVO NA CIÊNCIA DA INFORMAÇÃO}

Ao apresentar a teoria dos três mundos (mundo físico - material; mundo do conhecimento subjetivo - estados mentais e; mundo do conhecimento objetivo - os produtos da mente humana), Popper (1972) propiciou uma abertura necessária e relevante ao campo científico da Ciência da Informação com a adoção das interações entre os mundos do conhecimento subjetivo e do mundo do conhecimento objetivo. Tal estatuto torna-se peculiar ao reunir características que desmistificam e trazem perspectivas positivas para as pesquisas em Ciência da Informação, uma vez que a subjetividade enquanto abordagem investigativa assenta-se no processo cognitivo enquanto elemento subjacente em várias atividades de processamento e representação da informação.

De modo geral, a abordagem cognitiva relaciona-se aos estudos em torno do conhecimento humano, cujo foco é a cognição enquanto processo de aquisição de conhecimento por meio da mente humana. Na ótica de Capurro (1991), a forte inserção da abordagem cognitiva na Ciência da Informação decorre dos três paradigmas epistemológicos que sustentam o campo, a saber: o paradigma da representação (o ser vivente é cognoscente e, portanto, o processo de conhecer consiste na assimilação do mundo externo por meio da capacidade de criar 
representações dos objetos do mundo na mente), o paradigma da relação fontecanal-receptor (o fenômeno da comunicação humana aplicado a diferentes níveis de realidade) e o paradigma platônico (o conhecer é algo objetivo por si).

$\mathrm{Na}$ Ciência da Informação, o ponto de vista cognitivo "[...] implica que cada ato de processamento da informação, seja ele perceptível ou simbólico, é mediado por um sistema de categorias e conceitos os quais, para o mecanismo de processamento da informação, constituem um modelo de mundo" (De MEY, 1982, p.04). Uma das poucas verdades inquestionáveis é a de que os seres humanos são conhecedores e observadores da realidade, cujo processo de conhecer consiste na assimilação dos elementos por meio de suas representações mentais, as quais são processadas e codificadas pelo cérebro para então, serem comunicadas (CAPURRO, 1991). Ainda que não se queira ensinar um ser humano este é observador o suficiente para ser capaz de aprender. No entanto, o ato de querer conhecer (aprendizagem pelo ponto de vista do desejante) não consiste em um condicionamento, mas em uma vontade que se constrói em cada sujeito conforme as relações do seu grupo social frente ao conhecimento.

Neste sentido, entende-se que os estudos em Ciência da Informação não devem explorar os benefícios da abordagem cognitiva apenas na esfera do usuário, como recorrentemente proclamados, mas focalizar o profissional da informação enquanto elemento ímpar para o processamento e representação da informação. Toma-se por base a prerrogativa de que a compreensão da cognição humana dos profissionais na condição de sujeitos cognoscentes pode promover melhorias no processamento da informação nos diferentes domínios em que se apresenta. Adicionalmente, tem-se a cognição como um conhecimento necessário para que o profissional da informação compreenda e delineie a trajetória lógica de construção e apreensão do conhecimento.

Assim, com base na abordagem cognitiva a Ciência da Informação viabiliza pesquisas qualitativas que possibilitam observar o processo cognitivo dos profissionais da informação - seus procedimentos para a resolução de tarefas, o modo como organizam seu próprio conhecimento e, também, suas representações sobre o conhecimento assimilado ou adquirido. Nesta perspectiva, o enfoque na cognição dos profissionais da informação revela aspectos implícitos decorrentes das ações e interações para a construção de conhecimento, visto que o conhecimento 
enquanto processo cognitivo depende da informação para sua construção, uma vez que o conhecimento se adquire mediante a reflexão do pensamento, sendo uma certeza subjetiva ou mesmo conclusiva da existência de algo (DAHLBERG, 1993). Tal apontamento reforça a necessidade de abordar o profissional da informação enquanto ser pensante e indispensável para a promoção da socialização da informação nos diferentes contextos de informação.

Portanto, é com base neste pensamento que são dispostas a seguir algumas reflexões sobre o caminhar evolutivo da abordagem do ponto de vista cognitivo na Ciência da Informação e suas novas possibilidades investigativas frente as necessidades contemporâneas de informação de cunho socioculturais que permeiam a prática profissional.

\subsection{O Caminhar Evolutivo do Paradigma Cognitivo: a Perspectiva Sóciocognitiva}

Ao ser investigado apenas pelo prisma dos usuários, o paradigma cognitivo foi substituído pelo paradigma social e deixou de ser o cerne das investigações em Ciência da Informação, pois atou como um paradigma idealista e associal devido seu enfoque cognitivo individualista ao negligenciar os condicionamentos sociais e materiais do existir humano (FROHMANN, 1992).

Pode-se dizer que a questão paradigmática regeu a Ciência da Informação da seguinte maneira (CAPURRO, 2003; OLSON; BOOL, 2001): primeiramente, a Ciência da Informação nasce em meados do século XX como um paradigma físico, relacionado com a Teoria da Informação e diretamente associado à tecnologia, aos contextos de informação e à transmissão de mensagens - atualmente obsoleto por excluir o ser humano do processo de transmissão de informação, perdendo-se o sentido humano, prático e social da área. Neste, coloca-se o usuário em uma posição passiva ao manifestar suas necessidades intrínsecas de informação, tendo que se adaptar aos mecanismos dos sistemas de recuperação da informação. Posteriormente, assenta-se o paradigma cognitivo, no qual o sujeito deixa de ser um mero receptor passivo de informação e passa a atuar como um agente ativo entre a estrutura de informação e a estrutura conceitual própria. Por fim, tem-se o paradigma pragmático e social (SHERA, 1980), no qual a informação é tratada como 
matéria-prima básica que permite a geração de conhecimento, este último incorporado/inerente a um sujeito cognoscente. Neste, a geração de novos conhecimentos depende da assimilação de um sujeito e, consequentemente, de seu compartilhamento com outros, pois os paralelos dependentes - informação e conhecimento - apenas passam a ser funcionais quando utilizados e compartilhados no meio social.

Em linhas gerais, a dimensão social considera que o conhecimento e o conhecimento prévio dos sujeitos estão entrelaçados, de modo que essa rede social que os sustentam assegura o existir humano. Aqui, a realidade é socialmente construída e, neste caminhar, a informação deixa de ser um "dado" ou uma "coisa" e atua como um processo passível de percepção e compreensão sob variadas formas pelos sujeitos cognoscentes (BERGER; LUCKMANN, 1985).

Conforme essa nova concepção sociológica, o objeto e o método são elementos sociais contextualizados dentro de fluxos de informação e de conhecimento. Esse novo posicionamento acentua na Ciência da Informação uma natureza de trocas e interlocuções com os campos científicos correlatos, o que ampliou o foco das abordagens e a adoção de métodos diferenciados, uma vez que esta é uma imposição das problemáticas abordadas, visto que "a estrutura teórica de uma ciência nunca é completa ou fechada, oferece continuamente novos problemas" (BROOKES, 1980, p. 125).

Sob este entendimento, a Ciência da Informação passa a investigar os canais, os suportes e as estruturas de informação dentro dos domínios de conhecimento pela corrente sócio-construtivista a partir da década de 1990. Nesta, as abordagens cognitivas são analisadas e criticadas por diversos pesquisadores que, além de relevarem os processos cognitivos dos sujeitos para a realização de processos documentais e na construção de sistemas de recuperação da informação, passam a agregar o elemento "contexto" e a ressaltarem a visão sóciocognitiva na efetivação desse processo, em que:

O Paradigma Social enfoca a recuperação dos elementos subjetivos dos usuários para a definição do desenho dos sistemas de recuperação, considerando sua visão de mundo. A partir dessa concepção, a Ciência da Informação volta-se para um enfoque interpretativo, centrado no significado e no contexto social do usuário e do próprio sistema de recuperação da informação (ALMEIDA; BASTOS; BITTENCOURT, 2007, p. 22). 
Vê-se, então, que o paradigma social enfoca a visão holística e coletiva dos sujeitos cognoscentes, colocando-os numa posição interativa, seja para o processamento e representação da informação ou na delimitação das configurações do sistema de recuperação da informação, conforme observado no quadro 1, o qual retrata as concepções teórico-aplicadas que norteiam e caracterizam os paradigmas físico, cognitivo e social em Ciência da Informação.

Quadro 1 - Paradigmas da Ciência da Informação

\begin{tabular}{|c|c|c|c|}
\hline PARADIGMAS & ABORDAGENS & PROCESSOS & O OLHAR \\
\hline Físico & $\begin{array}{c}\text { Sistema/Base de } \\
\text { Dados }\end{array}$ & Tecnológicos & $\begin{array}{c}\text { Organização e } \\
\text { Tratamento da } \\
\text { Informação }\end{array}$ \\
\hline Cognitivo & Sujeito/Usuário & Psicológicos & $\begin{array}{c}\text { Organização } e \\
\text { Tratamento da } \\
\text { Informação }\end{array}$ \\
\hline Social & Domínio/Comunidade & Sociais e Culturais & $\begin{array}{c}\text { Informação } \\
\text { construída }\end{array}$ \\
\hline
\end{tabular}

Fonte: Adaptado de Nascimento (2006).

Nesta perspectiva, a informação enquanto elemento gerador de conhecimentos para o sujeito cognoscente e para o meio que o cerca está em constante movimento nos domínios individual e social e, portanto, num paradoxo de geração de conhecimento em nível individual e coletivo. Este novo olhar em torno da informação baseia-se, principalmente, nos fundamentos sócioculturais da cognição, em que muitos dos processos mentais são de ordem sóciocognitiva em sua origem (LURIA, 1990). Assim, as manifestações da consciência humana constituem-se por meio das práticas básicas das numerosas atividades humanas, à luz do contexto histórico, social e cultural, em que as capacidades cognitivas estão numa cultura episódica: sistema coletivo de conhecimento e comportamento.

Donald (1999, p. 20) esclarece que as capacidades cognitivas dos seres humanos afetam diretamente os tipos de cultura que produzem, pois os "[...] tipos específicos de cultura humana têm efeitos diretos sobre a cognição individual". Para o referido autor a especificidade da humanidade assenta-se na capacidade dos seres humanos para rápidas mudanças culturais. Nessa perspectiva, "essa dimensão não-material da cultura é a dimensão do conhecimento, que uma sociedade tem sobre si mesma, sobre outras sociedades, sobre o meio material em 
que vive e sobre a própria existência", em que essa produção cultural torna-se fator de mudança social a partir de novas formas de percepção da realidade, na qual a informação assume "características de elemento instituinte da cultura" (BORGES et al., 2003, p. 10-11).

Assim, a perspectiva sóciocultural não só atesta a construção cultural dos processos psicológicos cognitivos, por meio da apropriação de certos operadores culturais, mas entende as atividades sociais como garantia das intenções que se materializam em conduta eficaz. Com isso, o papel das interações na produção e organização dos sistemas sociais, independentemente de suas características, necessita de um entendimento sóciocognitivo, uma vez que as ações e os fenômenos são apreendidos quando consideradas as relações que os caracterizam, sendo tanto territoriais quanto transindividuais. Assim, verifica-se que, sendo a informação um produto humano, o sujeito cognoscente não deve ser excluído do processo. Então, uma vez que o sujeito não é um ser isolado, mas vive socialmente e recebe influência de seu meio, o contexto de enunciação e interlocução deve ser evidenciado.

O aprofundamento investigativo da abordagem cognitiva a partir da perspectiva sóciocognitiva ou sócio-construtivista apresentada por Hjørland (1996) torna-se de grande valia para a Ciência da Informação, uma vez que nesta nova dimensão cognitiva não se perde a dimensão social, mas admite-se que o sujeito possui formação coletiva e de sentido social, ou seja, todos os conceitos e sentidos são construções sociais; atentando-se em conjunto para as situações próprias de cada ser. Portanto, cada sujeito adquire e processa a informação de acordo com seu mapa cognitivo, prevalecendo suas condições sociais, culturais, educacionais, entre outras.

Como resultado, passa-se a considerar a informação como uma dimensão da existência humana que se constitui como fenômeno da esfera cultural dos seres humanos (CAPURRO, 1991). Sob este olhar, entende-se que a informação construída como prática social apresenta uma importante contribuição ao processamento da informação, uma vez que as estruturas de conhecimento devem ser explicadas a partir do contexto social do sujeito. Neste ponto, os esclarecimentos de Hjørland e Albrechtsen (1995) são pertinentes ao levantar questões relevantes e contribuírem para a compreensão do conceito de informação, pois na visão dos 
referidos autores a Ciência da Informação deve ser considerada muito mais como um campo social do que como um campo mental (cognitiva).

Conforme o contexto apresentado, vale esclarecer que o processo de transformação da informação objetiva em informação subjetiva pelo profissional da informação para atribuir significado aos conteúdos informacionais e gerar conhecimento depende de várias conexões cognitivas - da própria experiência obtida do meio e do auxílio da observação dos dados adquiridos por meio de fontes documentais (ALMEIDA; BASTOS; BITTENCOURT, 2007, p. 83). Desse modo, na esfera da Ciência da Informação, a produção do conhecimento abrange os aspectos intelectuais de apropriação da informação (cognição), bem como a representação e acessibilidade da mesma (contextos informacionais), "tornando essas duas frentes de estudo inseparáveis" (MAIMONE; SILVEIRA, 2007, p. 66).

Estas elucidações atestam a necessidade de pesquisas que primem pelo entendimento dos alicerces sociais do conhecimento e suas estratégias metodológicas (JACOB; SHAW, 1998). Verifica-se que este novo olhar investigativo ganha espaço e uma considerável aceitação nos discursos dos cientistas da informação, mas cabe salientar que as questões que regem este foco investigativo são muitas e sugerem pesquisas adicionais mediante os novos questionamentos, especificamente quando considerado as questões que permeiam o processamento da informação e o processo de conhecer do profissional da informação, ambos permeados por características de ordem cognitiva e social.

\section{CONSIDERAÇÕES FINAIS}

Sob um olhar interdisciplinar com as Ciências Cognitivas, o presente estudo teve como objetivo central refletir sobre o paradigma cognitivo em Ciência da Informação e sua evolução frente as necessidades contemporâneas de informação, mais especificamente no entorno do processo de conhecer do profissional da informação. Neste sentido, partiu-se de reflexões gerais em torno da interdisciplinaridade entre a Ciência da Informação e as Ciências Cognitivas e exposição das principais teorias em torno do desenvolvimento cognitivo. Tal orientação serviu de pano de fundo útil para a introdução de reflexões sobre o paradigma cognitivo na Ciência da Informação, mais propriamente para tecer 
considerações em torno do seu caminhar evolutivo e as novas abordagens assumidas nas pesquisas destinadas ao processamento e representação da informação, bem como do profissional da informação na condição de sujeito cognoscente.

De modo geral, as discussões aqui traçadas orientam para a necessidade de pesquisas que suscitem reflexões sobre o processo de conhecer do profissional da informação sob o viés da abordagem sociocognitiva, objetivando novos subsídios para a compreensão da relação "informação - manifestações cognitivas" ocorridas pela mente humana e suas implicações na dimensão social.

Neste sentido, entende-se que o profissional da informação na condição de sujeito cognoscente deve ser analisado dentro de seu contexto de interlocução. Portanto, as pesquisas centradas em questões relativas ao processamento da informação devem considerar não apenas os aspectos cognitivos que cercam o processo de conhecer do profissional da informação, mas, sobretudo, atentarem-se para os aspectos de orientação social que permeiam os diversos contextos de informação para que as atividades ligadas à produção, tratamento, organização e recuperação da informação ocorram de maneira mais proveitosa. O resultado esperado é uma análise mais precisa da realidade que cerca as ações dos profissionais da informação no entorno do processamento da informação e, consequentemente, o desenvolvimento de teorias e métodos cada vez mais pertinentes com a realidade que cerca a prática profissional atrelada a realidade própria dos contextos de informação.

Ademais, investigar o profissional da informação enquanto sujeito cognoscente apresenta-se como uma das mais importantes possibilidades de evolução em nível teórico-metodológico na Ciência da Informação, tanto em abordagem prática quanto pela interação com o meio e suas características específicas, uma vez que o ser humano é constituído por diversidades comportamentais. Neste processo, as Ciências Cognitivas contribuem no aspecto metodológico e fornecem um amplo quadro conceitual para o entendimento do processo de conhecer do profissional da informação atrelado a uma realidade social objetiva. 


\section{REFERÊNCIAS}

ALMEIDA, Carlos Cândido; BASTOS, Flávia Maria; BITTENCOURT, Fernando. Uma leitura dos fundamentos histórico-sociais da ciência da informação. Revista Eletrônica Informação e Cognição, São Paulo, v. 6, n. 1, p. 68-89, 2007. Disponível em: <http://www2.marilia.unesp.br/revistas/index.php/reic/article/view/749>. Acesso em: 23 jan. 2008.

ALVARENGA, Lídia. Representação do conhecimento na perspectiva da ciência da informação em tempo e espaço digitais. Encontros Bibli: Revista Eletrônica de Biblioteconomia e Ciência da Informação, Florianópolis, v. 8, n. 15, 2003. Disponível em: <http://www.periodicos.ufsc.br/index.php/eb/article/view/15182924.2003v8n15p18/5233>. Acesso em: 18 jan. 2009.

BARRETO, Aldo Albuquerque. Padrões de assimilação da informação... In: RODRIGUES, Georgette Medleg; LOPES, Ilza Lopes. Organização e representação do conhecimento na perspectiva da Ciência da Informação. Brasília: Thesaurus, 2003.

BELKIN, Nicholas J.; ROBERTSON, Stephen E. Information science and the phenomenon of information. Journal of the American Society for Information Science, Washington, v. 37, n. 4, p. 197-204, 1976.

BELKIN, Nicholas J. The cognitive viewpoint in information science. Journal of Information Science, Cambridge, v. 16, p. 11-15, 1990.

BERGER, Peter; LUCKMANN, Thomas. A construção social da realidade: tratado de sociologia do conhecimento. Petrópolis: Vozes, 1985.

BERNARD, Juan Antonio. Análisis y representación del conocimiento: aportaciones de la psicología cognitiva. Scire, Zaragoza, v. 1, n. 1, p. 57-80, jan./jun. 1995.

BORGES, Mônica Erichsen Nassif et al. Estudos cognitivos em ciência da informação. Encontros Bibli: Revista Eletrônica de Biblioteconomia e Ciência da Informação, Florianópolis, v. 8, n. 15, 2003. Disponível em: <http://www.periodicos.ufsc.br/index.php/eb/article/view/1518-2924.2003v8n15p1>. Acesso em: 15 mar. 2012.

BORKO, Harold. Information science: what is it? American Documentation, Washington, v. 19, n. 1, p. 3-5, 1968.

BROOKES, Bertran C. The foundations of Information Science: part I. philosophical aspects. Journal of Information Science, Amsterdam, v. 2, p. 125-133, 1980.

BRUNER, Jerome Seymour. Atos de significação. Porto Alegre: Artes médicas, 1997. 
CAMPOS, Luiz Fernando Barros; VENÂNCIO, Ludmila Salomão. Perspectivas em (in)formação: tendências e tensões entre abordagens físicas, cognitivas e emergentes. Transinformação, Campinas, v. 19, n. 2, p. 107-118, maio/ago. 2007. Disponível em: <http://revista.puc-campinas.edu.br/transinfo/viewissue.php?id=16>. Acesso em: 15 nov. 2008.

CAPURRO, Rafael. Epistemologia e ciência da informação. In: ENCONTRO NACIONAL DE PESQUISA EM CIÊNCIA DA INFORMAÇÃO - ENANCIB, 5., 2003, Belo Horizonte. Anais... Belo Horizonte: UFMG, 2003.

CAPURRO, Rafael. Foundations of information science: review and perspectives. In: INTERNATIONAL CONFERENCE ON CONCEPTIONS OF LIBRARY AND INFORMATION SCIENCE, 1991, Tampere. Proceedings... Tampere, University of Tampere, 1991. Disponível em: <http:www.capurro.de/tempere91.htm>. Acesso em: 20 de março de 2009.

DAHLBERG, Ingetraut. Knowledge organization: its scope and possibilities. Knowledge Organization, Würzburg, v. 20, n. 4, p. 211-222, 1993.

DE MEY, Marc. The cognitive paradigm: an integrated understanding of science development. Chicago: University of Chicago, 1982.

DONALD, Merlin. Origens do pensamento moderno. Lisboa: Fundação Caloreste Gulbenkia, 1999.

DUPUY, Jean-Pierre. Nas origens das ciências cognitivas. São Paulo: UNESP, 1996.

FLAVELL, John H.; MILLER, Patricia H.; MILLER, Scott A. Desenvolvimento cognitivo. 3. ed. Porto Alegre: Artmed, 1999.

FROHMANN, Bernd. The power of images: a discourse analysis of the cognitive viewpoint. Journal of Documentation, London, v. 48, n. 4, p. 365-386, 1992.

GALVÃO, Maria Cristiane Barbosa. A organização da informação na perspectiva da ciência da informação e a dinâmica da cultura científica. In: HOFFMANN, Wanda Aparecida Machado; FURNIVAL, Ariadne Chloe Mary. Olhar: ciência, tecnologia e sociedade. São Paulo: Pedro e João, 2008. p. 203-210.

GARDNER, Howard. A nova ciência da mente: uma história da revolução cognitiva. São Paulo: Editora da Universidade de São Paulo, 1996.

HJØRLAND, Birger; ALBRECHTSEN, Hanne. Toward a new horizon in information science: domain-analysis. Journal of the American Society for Information Science, Washington, v. 46, n. 6, p. 400-425, 1995.

HJØRLAND, Birger. Information seeking and subject representation. London: Grenwood Press, 1996. 
INGWERSEN, Peter. Cognitive perspectives of information retrieval interaction: elements of a cognitive ir theory. Journal of Documentation, London, v. 52, n. 1, p. 3-50, 1996.

JACOB, Elin K.; SHAW, Debora. Sociocognitive perspectives on representation. Annual Review of Information Science and Technology, Medford, v. 33, p. 131185, 1998.

JOB, Ivone. Estudos cognitivos e a representação do conhecimento na ciência da informação. Revista ACB: Biblioteconomia em Santa Catarina, Florianópolis, v. 13, n. 2, p. 365-378, jul./dez. 2008. Disponível em:

<http://revista.acbsc.org.br/index.php/racb/article/view/568>. Acesso em: 20 fev. 2009.

LE COADIC, Yves-François. A ciência da informação. Brasília: Briquet de Lemos, 1996.

LIMA, Gercina Ângela Borém. Interfaces entre a ciência da informação e a ciência cognitiva. Ciência da Informação, Brasília, v. 32, n. 1, jan./abr. 2003. Disponível em: <http://revista.ibict.br/ciinf/index.php/ciinf/article/view/133>. Acesso em: 14 jan. 2010.

LINARES, Radames. La presencia cognitive en ciencia de la información y su entorno. Ciência da Informação, Brasília, v. 33, n. 1, p. 33-37, jan./abr. 2004. Disponível em: <http://revista.ibict.br/ciinf/index.php/ciinf/article/view/41>. Acesso em: 23 abr. 2009.

LURIA, Aleksandr Romanovich. Desenvolvimento cognitivo. São Paulo: Ícone, 1990.

MAIMONE, Giovana Deliberati; SILVEIRA, Naira Christofoletti. Cognição humana e os paradigmas da ciência da informação. Revista Eletrônica Informação e Cognição, Marília, v. 6, n. 1, p. 55-67, 2007. Disponível em: <http://www.portalppgci.marilia.unesp.br/reic/viviewarticle.php?id=62>. Acesso em: 1 jun. 2008.

MATURANA, Humberto R. A ontologia da realidade. Belo Horizonte: Editora UFMG, 1997.

MIKHAILOV, Alexander Ivanovich; CHERNYI, Arkadii; GILYAREVSKYI, Rudhzero. Estrutura e principais propriedades da informação científica. In: GOMES, Hagar Espanha (Org.). Ciência da informação ou informática? Rio de Janeiro: Calunga, 1980. p. 71-89.

NASCIMENTO, Denise Morado. Abordagem sócio-cultural da informação.

Informação e Sociedade: Estudos, João Pessoa, v. 16, n. 2, p. 21-34, jul./dez. 2006. Disponível em:

<http://www.ies.ufpb.br/ojs2/index.php/ies/article/view/477/1474>. Acesso em: 20 abr. 2009. 
MUSSEN, Paul H et al. Desenvolvimento e personalidade da criança. São Paulo: Harbra, 1988.

OLSON, Hope A.; BOOL, John. J. Subject analysis in online catalog. 2. ed. Englewood: Libraries Unlimited, 2001.

PIAGET, Jean. A epistemologia genética. Petrópolis: Vozes, 1971.

POPPER, Karl. Objective knowledge: an evolutionary approach. London: Oxford, 1972.

ROZADOS, Helen Beatriz Frota. A ciência da informação em sua aproximação com as ciências cognitivas. Em questão, Porto Alegre, v. 9, n. 1, p. 79-94, jan./jun. 2003. Disponível em: <http://seer.ufrgs.br/EmQuestao/article/view/62/22>. Acesso em: 15 jun. 2010.

SANTANA, Suely de Melo; DIAS, Maria das Graças B. B.; ROAZZI, Antonio. Paradigmas do desenvolvimento cognitivo: uma breve retrospectiva. Estudos de Psicologia, Natal, v. 11, n. 1, p. 71-78, 2006.

SARACEVIC, Tefko. Ciência da informação: origem, evolução e relações.

Perspectivas em Ciência da Informação, Belo Horizonte, v. 1, n. 1, jan./jun. 1996. Disponível em: <http://portaldeperiodicos.eci.ufmg.br/index.php/pci/article/view/235>. Acesso em: 14 mar. 2009.

SARACEVIC, Tefko. Information science. Journal of the American Society for Information Science, Washington, v. 50, n. 12, p. 1051-1063, 1999.

SHERA, Jesse Hauk. Sobre biblioteconomia, documentação e ciência da informação. In: GOMES, Hagar Espanha (Org.). Ciência da informação ou informática? Rio de Janeiro: Calunga, 1980. p. 91-105.

VENÂNCIO, Ludmila Salomão; BORGES, Mônica Erichsen Nassif. Cognição situada: fundamentos e relações com a ciência da informação. Encontros Bibli: Revista Eletrônica de Biblioteconomia e Ciência da Informação, Florianópolis, n. 22, 2006. Disponível em: <http://www.periodicos.ufsc.br/index.php/eb/article/view/15182924.2006v11n22p30>. Acesso em: 23 nov. 2009.

WERSIG, Gernot.; NEVELLING, Ulrich. The phenomena of interest to Information Science. The Information Scientist, London, v. 9, n. 4, p. 127-140, 1975.

Title

Setting a new paradigm in cognitive science information: contributions to the process of knowing the information professional

\section{Abstract}

Introduction: Studies about human cognition represent a relevant perspective in information science, considering the subjective actions of information professionals and dialogic process 
that should permeate the activity of subjects dealing with the organization and representation of information.

Objective: Explore the approach of the cognitive perspective in information science and their new settings by contemporary needs of information to reflect on the process of meeting the professional information through the social reality that permeates the contexts of information.

Methodology: Reflection on theoretical aspects that deal with the cognitive development to discuss the implications of the cognitive approach in information science and its evolution in the scope of the representation and processing of information.

Results: Research in Information Science must consider issues of cognitive and social order that underlie information processing and the process of knowing the information professional as knowledge structures must be explained from the social context of knowing subjects.

Conclusions: There is a need to investigate the process of knowing the information professional in the bias of socio-cognitive approach, targeting new elements for the understanding of the relationship information (cognitive manifestations) and its implications on the social dimension.

Keywords: Information Science. Cognitive Sciences. Cognitive paradigm. Process of knowing. Information Professional.

\section{Título}

La nueva configuración del paradigma cognitivo en la ciencia de la información: contribuciones al proceso de conocer del profesional de la información

\section{Resumen}

Introducción: Los estudios en torno a la cognición humana representan una perspectiva relevante en Ciencia de la Información, considerándose las acciones subjetivas de los profesionales de la información y el proceso dialógico que debe permear la actuación de los sujetos que trabajan con la organización y con la representación de la información.

Objetivo: Explora el abordaje del punto de vista cognitivo en la Ciencia de la Información y sus nuevas configuraciones mediante las necesidades contemporáneas de información para reflexionar sobre el proceso de conocer del profesional de la información mediante la realidad social que permea los contextos de información.

Metodología: Reflexión sobre aspectos teóricos que tratan del desarrollo cognitivo para discutir las implicaciones del abordaje cognitivo en Ciencia de la Información y su evolución en el ámbito del procesamiento y representación de la información.

Resultados: La investigaciones en Ciencia de la Información deben considerar cuestiones de orden cognitiva y social que permean el procesamiento de la información y el proceso de conocer del profesional de la información, pues las estructuras de conocimiento deben ser explicadas a partir del contexto social de los sujetos cognoscentes.

Conclusiones: Es necesario investigar el proceso de conocer del profesional de la información bajo el abordaje socio-cognitivo, objetivando nuevos subsidios para la comprensión de la relación información (manifestaciones cognitivas) y sus implicaciones en la dimensión social.

Palabras clave: Ciencia de la Información. Ciencias Cognitivas. Paradigma cognitivo. Proceso de conocer. Profesional de la información.

Recebido em: 20.08.2012

Aceito em: 10.05.2013 